\title{
Nutritional condition in the dry period is related to the incidence of postpartum subclinical endometritis in dairy cattle
}

\author{
Asako Taniguchi ${ }^{1}$, Tatsuya Nishikawa ${ }^{1}$, and Yasuhiro Morita ${ }^{2,3, *}$
}

* Corresponding Author: Yasuhiro Morita Tel: +81-561-37-0202, Fax: +81-561-38-4473,

E-mail:ymorita@agr.nagoya-u.ac.jp

${ }^{1}$ Okayama Prefectural Federation Agricultural Mutual Aid Association, Okayama 700-8602, Japan

${ }^{2}$ Graduate School of Bioagricultural Sciences, Nagoya University, Nagoya 464-8601, Japan ${ }^{3}$ Asian Satellite Campuses Institute, Nagoya University, Nagoya 464-8601, Japan

\section{ORCID}

Asako Taniguchi

https://orcid.org/0000-0002-4315-5606

Tatsuya Nishikawa

https://orcid.org/0000-0002-0130-583X

Yasuhiro Morita

https://orcid.org/0000-0001-7364-3187

Submitted Mar 31, 2020; Revised May 13, 2020; Accepted Jun 20, 2020
Objective: Endometritis is a major disease, that causes infertility in cattle, and is usually categorized as clinical or subclinical endometritis (SCE). The nutritional condition during the dry period is important for recovery after the last stage of the lactation period, and for postpartum production and reproduction. This study aimed to clarify the relationship between nutritional and metabolic characteristics in the dry period, and the risk of postpartum SCE.

Methods: Multiparous Holstein dairy cows $(\mathrm{n}=25$, raised in a tied stall) were used. Endometrial cytological analysis was performed around 30 days post-partum, with 5\% to $14 \%$ polymorphonuclear (PMN) as a cut-off point to define SCE. Serum levels of glucose, non-esterified fatty acids, $\beta$-hydroxybutyric acid (BHBA), blood urea nitrogen, total cholesterol, aspartate aminotransferase, $\gamma$-glutamyl transpeptidase, calcium, phosphorus, and magnesium were measured in the cows at the dry period to evaluate energy status, protein metabolism, and mineral metabolism.

Results: The incidence of SCE in the cows was $60.0 \%(n=15 / 25)$ and the mean PMN\% in postpartum cows diagnosed as SCE was $8.05 \% \pm 2.6 \%$. Overall, 17 and 8 samples were collected from the cows in the far-off and close-up periods, respectively. The serum concentration of BHBA in the far-off period and serum glucose concentration in the closeup period were correlated with postpartum $\mathrm{PMN} \%(\mathrm{r}=0.62, \mathrm{p}<0.01 ; \mathrm{r}=-0.74, \mathrm{p}<0.05$, respectively). Serum levels of calcium and magnesium in the dry period were associated with the incidence of postpartum SCE (healthy vs SCE cows, $\mathrm{p}<0.05$ ).

Conclusion: Blood levels of glucose, BHBA, calcium, and magnesium in dry periods could be useful parameters for predicting the risk of postpartum SCE. The present study also suggests that management in the close-up period is essential for promoting recovery from calving fatigue.

Keywords: Dairy Cattle; Dry Period; Metabolic Parameter; Nutrition; Subclinical Endometritis

\section{INTRODUCTION}

Endometritis is a disease that often causes infertility in cattle. Infection and inflammation of the uterus and cervix affects approximately one-third of dairy cows, resulting in a substantial negative impact on the probability and timing of pregnancy [1]. Disruption of the epithelium, an increase in blood flow, edema, and an influx of inflammatory cells, mostly neutrophils and lymphocytes, are often observed in the cows contracting endometritis $[2,3]$. Consequently, endometritis generally causes an increase in the number of artificial inseminations (AIs) required per pregnancy, a delay of the first AI timing after calving, a decrease in pregnancy rate, and an increase in calving interval.

Endometritis is defined as an inflammation of the endometrium, but not of the stratum spongiosum $[3,4]$, and is usually categorized into the clinical (CE) or subclinical (SCE) 
levels. The CE typically occurs within 21 days postpartum (DPP) [5] and is defined by the detection of purulent $(>50 \%$ pus) discharge between 20 and 33 DPP, or mucopurulent (approximately $50 \%$ pus and 50\% mucus) discharge between 26 and 33 DPP, either by an observation of the external perineum or by use of a vaginoscope [6,7]. Conversely, the SCE is not characterized by a uterine discharge. Therefore, endometrial cytology, which is based on the presence of cellular evidence of inflammation, is currently considered to be the most useful method to diagnose both types of endometritis [3]. The percentage of polymorphonuclear (PMN) cells, calculated from the total number of the PMN and endometritis cells obtained by uterus lavage or cytobrush [8], has been usually used to define both, CE and SCE. To date, several definitions of endometritis have been postulated; $5 \%$ PMN is adequate as a diagnostic criterion for SCE at 21 to 56 DPP in some studies $[9,10]$, while others stated that $14 \%$ PMN is a suitable threshold for diagnosing CE at 4 weeks after the delivery [11], or 18\% PMN at 20 to $33 \mathrm{DPP}$ is a better threshold for diagnosing CE [12]. Thus, the percentage of $\mathrm{PMN}$ is a particularly important indicator for improving SCE treatment.

It has been reported that a severe negative energy balance (NEB) caused by a reduced feed intake, which often causes an increase in serum non-esterified fatty acids (NEFA), and then disturbed immune function in the transition period are related to an incidence of endometritis $[13,14]$. However, there have been few studies on the relationship between the antepartum nutritional condition and the incidence of postpartum endometritis, particularly SCE. Most related reports to date have focused on postpartum nutrient conditions and uterine recovery and infection.

The dry period is important for recovery after the previous lactation period. The dry period can be divided into the close-up and far-off periods, which are least 3 and 4 to 6 weeks before the expected parturition, respectively. Many reports to date have indicated an importance of specific management during the close-up and far-off periods separately. In particular, the close-up period is important for fetal growth, and consequently, the cow requires more energy and protein in this period than during the far-off period [15]. Therefore, for transition success, energy supplementation should be provided to cows during the close-up period. Moreover, other studies have suggested that excessive energy intake during the far-off period had a more negative effect on metabolism after delivery than overfeeding during the close-up period [16,17]. Conversely, the far-off period is important for adaptation of the rumen environment prior to delivery [18]. Therefore, in terms of the effect of energy management, the far-off period and the close-up period should be considered separately.

The present study investigated the relationship between the antepartum nutritional condition and the incidence of postpartum SCE in dairy cattle, with a focus on the difference in metabolism conditions and energy demands among the dry, far-off, and close-up periods separately. We aimed to evaluate the risk factors related to the incidence of SCE after the transition period, and the factors essential for preventing postpartum uterine infection, by measuring the blood nutritional and metabolic parameters in the dry period.

\section{MATERIALS AND METHODS}

\section{Animals and experiment design}

Multiparous, healthy, Holstein dairy cows ( $\mathrm{n}=25$; average age, 4.32 years) raised in Okayama Prefecture, Japan (mainly around $35^{\circ} 1^{\prime} \mathrm{N} 134^{\circ} 0^{\prime} \mathrm{E}$, Tsuyama City), were selected in the present study. All cows were managed with tie-stall housing, following the recommendations of the Ministry of Agriculture and Forestry and Fishery in Japan; they were fed nutritionally adequate fodder (containing maize and whole crop rice silage [19], multiple types of hay (sudan grass, orchard grass, oats grass, timothy grass, and alfalfa), grain and soy mixed concentrate, beet pulp, and fatty and amino acid supplementation) as per the National Research Council (NRC) 2001 guidelines [20] for multiparous cows of $700 \mathrm{~kg}$ body weight, with approximately $35 \mathrm{~kg}$ (early and middle lactation) and $25 \mathrm{~kg}$ (middle to late lactation) milk yield per day per cow in each farm. Forage and concentration were fed separately three to five times a day depending on the farmers' system. Water was available ad libitum from a water cup system. All experimental procedures were approved by the Committee for the Care and Use of Experimental Animals at Okayama Prefectural Federal Agricultural Mutual Aid Association (approval number Seiju H29-46).

We investigated the relationship between nutritional/ metabolic indices and the risk of postpartum SCE in healthy transition cows in the dry period. We defined the close-up period as the last 3 weeks before parturition and the far-off period as the dry period before the close-up period. Blood sampling and body condition score (BCS) determination were performed 3 to 4 hours after the morning feeding following milking. Each cow was treated in these procedures once in the dry periods. Blood samples were collected in $10 \mathrm{~mL}$ plain vacuum-tubes coated with coagulation activator (Venoject, Terumo Corp., Tokyo, Japan) for serum collection, and $5 \mathrm{~mL}$ Ca-ethylenediaminetetraacetic acid vacuumtubes (Venoject, Terumo Corp., Japan) for complete blood count $(\mathrm{CBC})$ samples, via aseptic caudal venipuncture using an 18-gauge needle after determination of the BCS. Blood samples were immediately placed on ice before centrifugation at $1,500 \times \mathrm{g}$ for $15 \mathrm{~min}$. Serum was taken and stored at $4^{\circ} \mathrm{C}$ for subsequent analysis of metabolites on the same day. The mean time point of blood sampling in the close-up and 
far-off periods in the present study were 13.8 \pm 5.7 days and $40.6 \pm 11.8$ days (means \pm standard deviation), respectively.

\section{Cytological determination of endometritis}

Cytological sampling of the endometrium was performed at approximately $30 \mathrm{DPP}$ (27 to $40 \mathrm{DPP}$, median $34 \mathrm{DPP}$ ) by cytobrush (Metribrush, Fujihira Industry Co Ltd., Tokyo, Japan). Cytology slides were prepared by rolling the cytobrush on a clean microscope slideglass, immediately followed by fixation with a cytofixative (CytokeepII, Alfresa Pharma Co., Osaka, Japan) in the field. The slideglasses were subsequently stained with Diff-Quik (Sysmex, Kobe, Japan) for 20 seconds. The percent of polymorphonuclear leukocytes (PMN\%) was assessed by counting a minimum of 200 cells at $400 \times$ magnification, to provide a quantitative assessment of endometrial inflammation. The prepared slides were assessed twice by two clinicians, one of whom collected the samples, and another did not, as in the study by Wagener et al [10]. We set $5 \%$ to $14 \%$ as the cut-off PMN\% for defining the SCE; 5\% $\mathrm{PMN}$ is considered adequate for diagnosing SCE at 21 to 62 DPP $[9,10]$ while $14 \%$ PMN\% is used as the CE threshold [11]. Cytological samples in $\mathrm{PMN} \%<4,5<\mathrm{PMN} \%<14,15<$ $\mathrm{PMN} \%$ were categorized as normal, SCE, and CE, respectively. All cows except for those diagnosed with $\mathrm{CE}$ were analyzed in this study.

\section{Measurement of serum levels of energetic and} metabolic substances and complete blood counts

Serum samples were subjected to analysis for concentrations of glucose (Glu), NEFA, $\beta$-hydroxybutyric acid (BHBA), blood urea nitrogen (BUN), total cholesterol (T-chol), aspartate aminotransferase (AST), $\gamma$-glutamyl transpeptidase (GGT), calcium $(\mathrm{Ca})$, phosphorus $(\mathrm{P})$, and magnesium $(\mathrm{Mg})$ using the automation biochemical analyzer (7180, Hitachi HighTechnologies Corporation, Tokyo, Japan). Glu, NEFA, BHBA, and BCS were evaluated as parameters for the energy status, T-chol, BUN, AST, and GGT were evaluated as parameters for protein metabolism, and $\mathrm{Ca}, \mathrm{Mg}$, and $\mathrm{P}$ were evaluated as parameters for mineral metabolism. The $\mathrm{CBC}$ was evaluated using an automatic hematology analyzer (Celltak Alpha, MEK-6450, NIHON KOHDEN, Tokyo, Japan).

\section{Statistical analysis}

The correlation coefficient between post parturition PMN\% and parameters from blood analysis in the close-up and faroff periods was determined using the Pearson's productmoment correlation test. Blood metabolic parameters were compared between non-SCE (normal, $\mathrm{PMN} \%<5$ ) cows and SCE cows using the Student's t-test. All statistical analyses were conducted using algorithms in R version 3.5.1 (http:// www.R- project.org/), stats R package.

\section{RESULTS}

Summary of postpartum endometrial status and blood parameters in dry periods in cows

None of the cows in this study showed placental retention or other uterine diseases after calving. The incidence of SCE in the assigned cows was $60.0 \%(15 / 25)$ and the mean PMN\% in cows diagnosed with postpartum SCE was $8.05 \% \pm 2.6 \%$ (Table 1).

\section{Correlation between postpartum PMN\% and blood parameters in the dry period in cows}

In the present study, no abnormal $\mathrm{CBC}$ values were observed in the white and red blood cell count, platelet count, and hematocrit value. Blood serum parameters in the dry periods related to nutritional metabolism; the correlation coefficient between postpartum PMN\% and blood serum parameters in the dry periods are shown in Table 1 and 2, respectively. The serum concentration of BHBA in the far-off period positively correlated with the postpartum PMN\% $(\mathrm{r}=0.62$, $\mathrm{p}<$ 0.01) (Table 2; Figure 1). In the close-up period, the serum concentration of Glu had a significantly negative correlation with postpartum $\mathrm{PMN} \%(\mathrm{r}=-0.74, \mathrm{p}<0.05)$, while NEFA, AST, and Ca levels were negatively correlated with PMN\% ( $\mathrm{r}$ $=-0.41,-0.43,-0.51$, respectively).

\section{Comparison of normal and subclinical endometritis} cattle in terms of blood parameters in dry periods Only mineral parameters through the dry periods were correlated with the incidence of postpartum SCE. The serum concentration of $\mathrm{Ca}$ and $\mathrm{Mg}$ differed significantly between normal (non-SCE) and SCE cattle $(\mathrm{p}<0.05)$. Other energy

Table 1. Status of postpartum endometrial infection and results of metabolic blood parameters in the dry periods

\begin{tabular}{|c|c|c|}
\hline Items & $\begin{array}{l}\text { Close-up } \\
(\mathrm{n}=8)\end{array}$ & $\begin{array}{l}\text { Far-off } \\
(n=17)\end{array}$ \\
\hline \multicolumn{3}{|l|}{ Incidence of postpartum SCE } \\
\hline $\mathrm{n}$ & $5 / 8$ & $10 / 17$ \\
\hline$\%$ & \multicolumn{2}{|c|}{60.0} \\
\hline $\begin{array}{l}\text { Average of postpartum PMN\% } \\
\text { in SCE cows (\%) }\end{array}$ & \multicolumn{2}{|c|}{$8.05 \pm 2.6$} \\
\hline Body condition score & $3.3 \pm 0.4$ & $3.3 \pm 0.3$ \\
\hline Glucose (mg/dL) & $60.5 \pm 5.4$ & $60.2 \pm 0.4$ \\
\hline Non-esterified fatty acids ( $\mu \mathrm{Eq} / \mathrm{L})$ & $200.0 \pm 236.3$ & $190.3 \pm 166.8$ \\
\hline$\beta$-Hydroxybutyric acid ( $\mu \mathrm{mol} / \mathrm{L})$ & $602.8 \pm 139.9$ & $532.5 \pm 172.4$ \\
\hline Total cholesterol (mg/dL) & $99.0 \pm 8.5$ & $131.9 \pm 50.2$ \\
\hline Blood urea nitrogen $(\mathrm{mg} / \mathrm{dL})$ & $9.5 \pm 3.5$ & $10.1 \pm 3.7$ \\
\hline Aspartate aminotransferase (IU/L) & $60.5 \pm 11.6$ & $56.4 \pm 10.8$ \\
\hline Y-Glutamyl transpeptidase (IU/L) & $22.0 \pm 6.3$ & $23.2 \pm 4.7$ \\
\hline Calcium (mg/dL) & $9.9 \pm 0.3$ & $10.0 \pm 0.4$ \\
\hline Phosphorus (mg/dL) & $6.1 \pm 1.0$ & $6.8 \pm 1.2$ \\
\hline Magnesium (mg/dL) & $2.4 \pm 0.2$ & $2.4 \pm 0.2$ \\
\hline
\end{tabular}

SCE, subclinical endometritis; PMN, polymorphonuclear cells. 
Table 2. Correlation coefficient between postpartum percentage of polymorphonuclear and parameters from blood analysis

\begin{tabular}{ccccccccccccc}
\hline & Periods & BCS & Glu & NEFA & BHBA & T-Chol & BUN & AST & GGT & Ca & P & Mg \\
\hline PMN\% & $\begin{array}{c}\text { Close-up } \\
(n=8)\end{array}$ & -0.13 & $-0.74^{\star}$ & -0.41 & -0.22 & 0.1 & -0.15 & -0.43 & 0.2 & -0.51 & -0.15 & 0.31 \\
& $\begin{array}{c}\text { Far-off } \\
(n=17)\end{array}$ & 0.14 & 0.21 & -0.25 & $0.62 * \star$ & 0.25 & -0.13 & -0.16 & 0.18 & -0.10 & 0.2 & -0.11 \\
& & & & & & & & & & & & \\
\hline
\end{tabular}

PMN\%, percentage of polymorphonuclear; BCS, body condition score; Glu, glucose; NEFA, non-esterified fatty acids, BHBA, $\beta$-hydroxybutyric acid, T-Chol, total cholesterol; BUN, blood urea nitrogen; AST, aspartate aminotransferase; GGT, y-glutamyl transpeptidase; Ca, calcium; P, phosphorus; Mg, magnesium. * Indicates significant differences $(p<0.05)$ as determined by Pearson's product-moment correlation.

** Indicates significant differences $(p<0.01)$ as determined by Pearson's product-moment correlation.

(a)
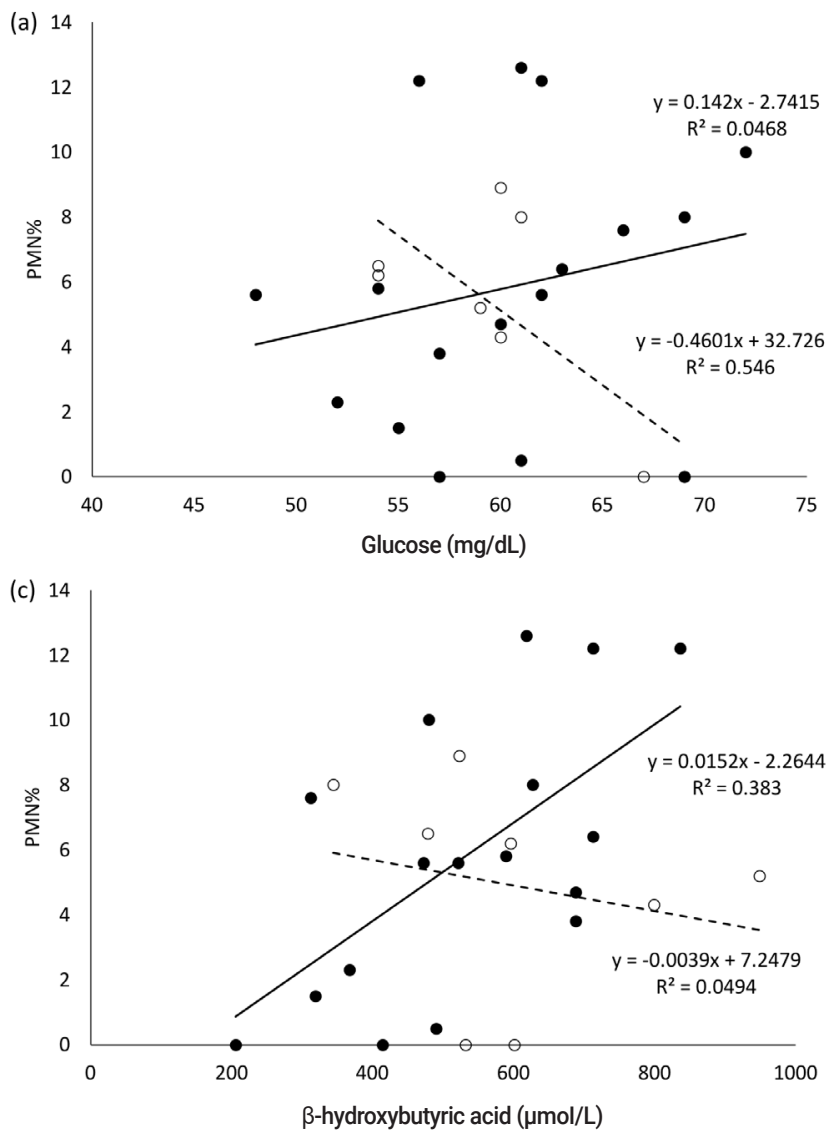

(b)

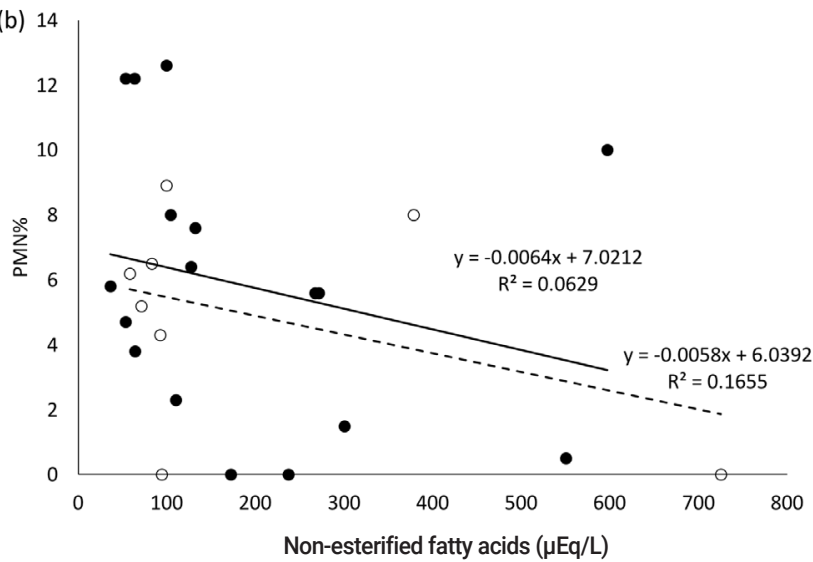

Figure 1. Relationship between postpartum PMN\% and serum glucose (a), non-esterified fatty acids (b), and $\beta$-hydroxybutyric acid (c) concentration in the respective dry periods. Open circles show samples of the close-up period and closed circles shows samples of the far-off period.

and protein metabolism parameters except for T-chol were not correlated with the incidence of SCE through the dry periods. T-chol tended to be correlated with the incidence of SCE $(\mathrm{p}<0.1)$ (Figure 2).

\section{DISCUSSION}

The present study demonstrated correlations between energy parameters (Glu and BHBA) in the dry periods and PMN\% after delivery, suggesting that the energy status of blood parameters in the dry periods is a risk factor for postpartum SCE, and these parameters may predict the occurrence of
SCE.

In the present study, all samples were obtained from healthy cows diagnosed by physical examination; the Glu level during the close-up period was negatively correlated with PMN\%. This result may indicate that the serum Glu level in the closeup period is important for postpartum uterine infections and the immune response, even if the cow appears healthy. Reynolds et al [21] reported that the splanchnic output of Glu in the transition period results almost completely from increased hepatic gluconeogenesis, and rate increases by $256 \%$. In addition, a previous study indicated that the serum Glu level is an indicator of NEB in the close-up period and 
(a)

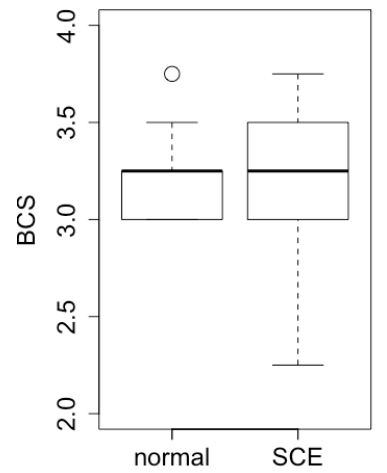

(e)

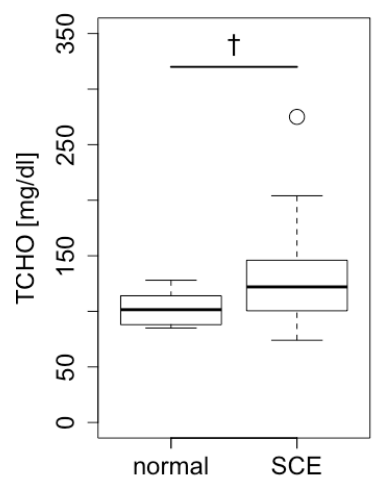

(i)

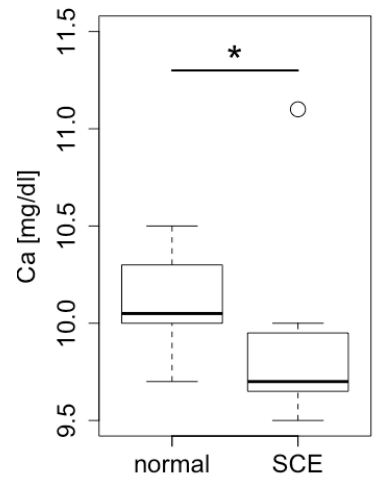

(b)

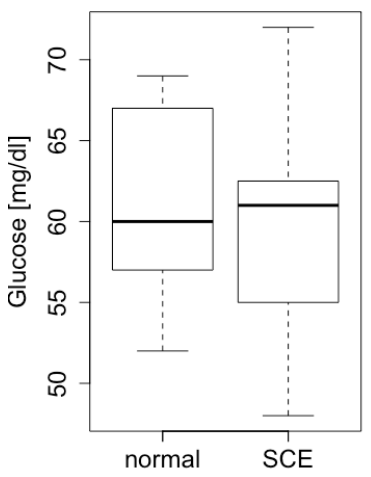

(f)

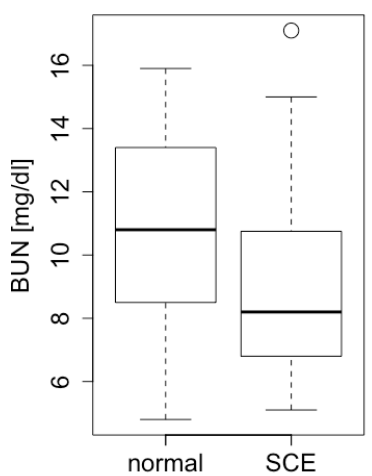

(j)

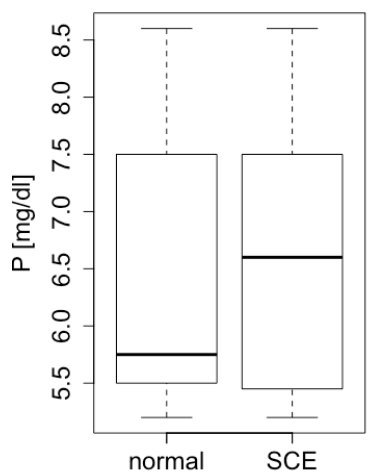

(c)

(d)
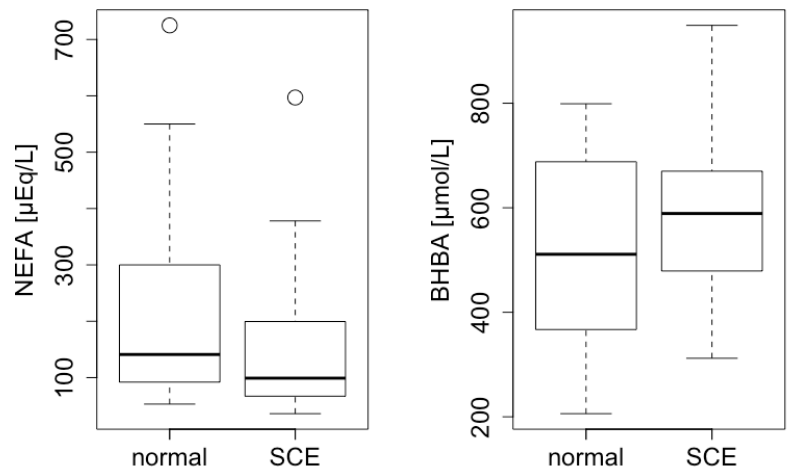

(g)

(h)
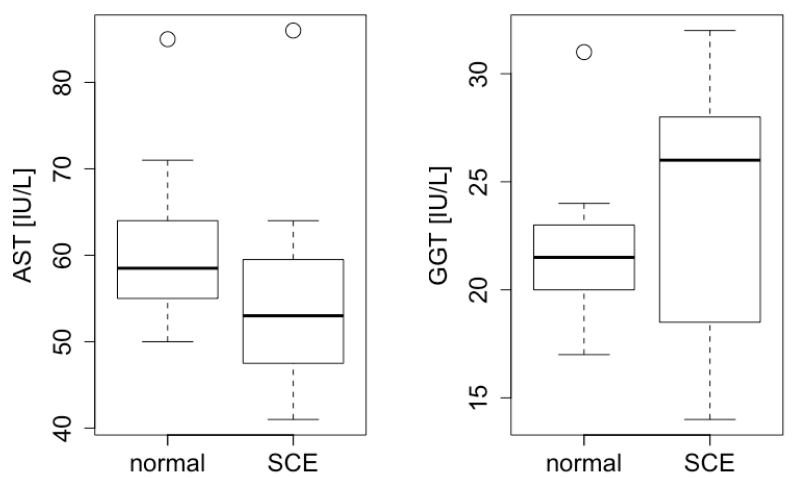

(k)

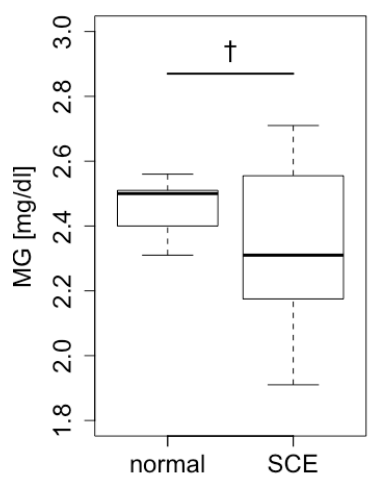

Figure 2. Comparison between normal cattle and subclinical endometritis (SCE) cattle in terms of postpartum blood parameters in the dry periods. (a) Body condition score (BCS), (b) Glucose, (c) non-esterified fatty acids (NEFA), (d) $\beta$-hydroxybutyric acid (BHBA), (e) total cholesterol (T-Chol), (f) blood urea nitrogen (BUN), (g) aspartate aminotransferase (AST), (h) y-glutamyl transpeptidase (GGT), (i) calcium (Ca), and (j) phosphorus (P), and (k) magnesium (Mg). Serum concentrations of calcium and magnesium differed significantly between normal and SCE cattle (Student's t-test, * p<0.05). Total cholesterol also showed a tendency for significance (Student's $t$-test, $\uparrow p<0.1$ ).

affects regulation of genes related to inflammation [14,22]. Therefore, low serum Glu concentrations before calving may indicate that the cow has an underactive liver; therefore, the serum Glu level in the close-up period may be an indicator of the liver status. Gluconeogenesis in dairy cattle is also regulated by several hormones such as insulin, glucagon, somatotropin, and cortisol, in general. Thus, the transition of blood Glu concentration for the energy status in the dry period could be affected by a cooperative response in these endocrine parameters, also finally resulting in suppression of the uterine immune function via changes in the wholebody immune response. We also described that blood levels 
of NEFA in the close-up period had a weak correlation with the postpartum PMN\% and NEFA, that could be important parameters for improving postpartum uterine conditions. The NEFA level was reported to be a risk factor for fatty liver $[23,24]$ and may therefore interfere with neutrophil function in vitro [25]. Indeed, a previous study suggested that blood levels of NEFA at a week before the expected calving time may be a useful dietary indicator for manage cows' health during the transition period [26].

Our results indicated that BHBA in the dry periods is also essential for conserving postpartum immune responses. Other previous reports also have suggested when NEFA is over transported to the liver leading to accumulating BHBA and other ketone bodies, and when BHBA and other ketones are elevated in the dry period, immune cell function against infection is decreased after delivery [13], and increase in BHBA suppresses phagocytosis, extracellular trap formation, and removal of bacteria by PMN cells [22]. In addition, nutritional conditions during the far-off dry period significantly affects the periparturient metabolic response, regardless of the close-up feeding scheme used [17]. Evaluation of the nutritional condition by measuring blood parameters for energy status during the far-off period could be important for nutritional management during the close-up period.

There was a weak correlation between the postpartum PMN\% and blood levels of AST in the close-up period in the present study, also suggesting that AST is an important parameter for improving postpartum uterine conditions. Sattler and Fürll [27] showed a significant correlation between AST and the degree of endometritis, suggesting that the energy and protein status in the transition period in dairy cows, particularly in the close-up period, is essential for improving the postpartum uterine condition and avoiding uterine infection.

The present study demonstrated that Ca levels in the closeup period showed a weak correlation with the postpartum PMN\%. Previous studies showed that the blood Ca level in cows with uterine disease decreased compared to that of healthy cows; consequently, $\mathrm{Ca}$ is an important second messenger for PMN activation [22]. Conversely, another study showed that the demand for both, energy and Ca increases in late pregnancy period when calf growth increases [28]. Thus, serum Ca parameters in the close-up period may also by a useful indicator for predicting the postpartum uterine condition. Moreover, the present study also suggests that the plasma Mg level in the dry period was related to the SCE incidence. $\mathrm{Mg}$ is known to be related to Ca excretion in urine; $\mathrm{Ca}$ excretion tends to decrease when $\mathrm{Mg}$ excretion increases [29]. Therefore, a high blood Mg concentration could support maintenance of $\mathrm{Ca}$ concentrations in the circulation of healthy cows; this may consequently suppress the development of postpartum SCE in the dry period.
In conclusion, blood parameters of the energy status (Glu and NEFA in the close-up period, and BHBA in the far-off period) and mineral status ( $\mathrm{Ca}$ and $\mathrm{Mg}$ ) in the dry periods could be useful parameters for predicting the risk of onset of postpartum uterine infections. These parameters would also provide concentration management strategies for the prevention of uterine dysfunction in nutritional aspects. In addition, the present study suggests that nutritional management, particularly energy metabolism, is essential in the close-up period to promote recovery from calving fatigue in the postpartum period.

\section{CONFLICT OF INTEREST}

We certify that there is no conflict of interest with any financial organization regarding the material discussed in the manuscript.

\section{ACKNOWLEDGMENTS}

The authors would like to thank all staff members of the Reproductive Working Group of Okayama Prefectural Federal Agricultural Mutual Aid Association (PFAMAA) for their technical support during the examination. The authors also appreciate the contributions of Dr. Hiroko Tsukamura and Dr. Satoshi Ohkura, Nagoya University, for their helpful advice.

\section{REFERENCES}

1. LeBlanc SJ, Osawa T, Dubuc J. Reproductive tract defense and disease in postpartum dairy cows. Theriogenology 2011; 76:1610-8. https://doi.org/10.1016/j.theriogenology.2011.07. 017

2. LeBlanc SJ. Postpartum uterine disease and dairy herd reproductive performance: a review. Vet J 2008;176:102-14. https:// doi.org/10.1016/j.tvjl.2007.12.019

3. Palmer C. Postpartum uterine infection. In: Hopper RM, editor. Bovine reproduction. Hoboken, NJ, USA: John Wiley \& Sons; 2014. pp. 440-8.

4. Bondurant RH. Inflammation in the bovine female reproductive tract. J Anim Sci 1999;77(Suppl 2):101-10. https:// doi.org/10.2527/1999.77suppl_2101x

5. Sheldon IM, Lewis GS, LeBlanc S, Gilbert RO. Defining postpartum uterine disease in cattle. Theriogenology 2006;65: 1516-30. https://doi.org/10.1016/j.theriogenology.2005.08. 021

6. Dubuc J, Duffield TF, Leslie KE, Walton JS, LeBlanc SJ. Definitions and diagnosis of postpartum endometritis in dairy cows. J Dairy Sci 2010;93:5225-33. https://doi.org/10.3168/ jds.2010-3428

7. Gobikrushanth M, Salehi R, Ambrose DJ, Colazo MG. Cate- 
gorization of endometritis and its association with ovarian follicular growth and ovulation, reproductive performance, dry matter intake, and milk yield in dairy cattle. Theriogenology 2016;86:1842-9. https://doi.org/10.1016/j.theriogenology. 2016.06.003

8. Barlund CS, Carruthers TD, Waldner CL, Palmer CW. A comparison of diagnostic techniques for postpartum endometritis in dairy cattle. Theriogenology 2008;69:714-23. https:// doi.org/10.1016/j.theriogenology.2007.12.005

9. Madoz LV, Giuliodori MJ, Jaureguiberry M, Plöntzke J, Drillich M, de la Sota RL. The relationship between endometrial cytology during estrous cycle and cutoff points for the diagnosis of subclinical endometritis in grazing dairy cows. J Dairy Sci 2013;96:4333-9. https://doi.org/10.3168/ jds.2012-6269

10. Wagener K, Gabler C, Drillich M. A review of the ongoing discussion about definition, diagnosis and pathomechanism of subclinical endometritis in dairy cows. Theriogenology 2017;94:21-30. https://doi.org/10.1016/j.theriogenology.2017. 02.005

11.Lee SC, Jeong JK, Choi IS, et al. Cytological endometritis in dairy cows: diagnostic threshold, risk factors, and impact on reproductive performance. J Vet Sci 2018;19:301-8. https:// doi.org/10.4142/jvs.2018.19.2.301

12. Kaufmann TB, Drillich M, Tenhagen BA, Heuwieser W. Correlations between periparturient serum concentrations of non-esterified fatty acids, beta-hydroxybutyric acid, bilirubin, and urea and the occurrence of clinical and subclinical postpartum bovine endometritis. BMC Vet Res 2010;6:47. https:// doi.org/10.1186/1746-6148-6-47

13. Hammon DS, Evjen IM, Dhiman TR, Goff JP, Walters JL. Neutrophil function and energy status in Holstein cows with uterine health disorders. Vet Immunol Immunopathol 2006; 113:21-9. https://doi.org/10.1016/j.vetimm.2006.03.022

14. Esposito G, Irons PC, Webb EC, Chapwanya A. Interactions between negative energy balance, metabolic diseases, uterine health and immune response in transition dairy cows. Anim Reprod Sci 2014;144:60-71. https://doi.org/10.1016/j.anire prosci.2013.11.007

15. Winkelman LA, Elsasser TH, Reynolds CK. Limit-feeding a high-energy diet to meet energy requirements in the dry period alters plasma metabolite concentrations but does not affect intake or milk production in early lactation. J Dairy Sci 2008;91:1067-79. https://doi.org/10.3168/jds.2007-0434

16.Janovick NA, Drackley JK. Prepartum dietary management of energy intake affects postpartum intake and lactation performance by primiparous and multiparous Holstein cows. J Dairy Sci 2010;93:3086-102. https://doi.org/10.3168/jds. 2009-2656

17.Dann HM, Litherland NB, Underwood JP, et al. Diets during far-off and close-up dry periods affect periparturient metabolism and lactation in multiparous cows. J Dairy Sci 2006;
89:3563-77. https://doi.org/10.3168/jds.S0022-0302(06)72 396-7

18. Beever DE. The impact of controlled nutrition during the dry period on dairy cow health, fertility and performance. Anim Reprod Sci 2006;96:212-26. https://doi.org/10.1016/j. anireprosci.2006.08.002

19. Islam MR, Ishida M, Ando S, Nishida T, Yoshida N. Estimation of nutritive value of whole crop rice silage and its effect on milk production performance by dairy cows. Asian-Australas J Anim Sci 2004;17:1383-9. https://doi.org/10.5713/ajas.2004. 1383

20.Committee on Animal Nutrition, National Research Council. Nutrient requirements of dairy cattle. 7th ed. Washington, DC, USA: National Academies Press; 2001.

21. Reynolds CK, Aikman PC, Lupoli B, Humphries DJ, Beever DE. Splanchnic metabolism of dairy cows during the transition from late gestation through early lactation. J Dairy Sci 2003; 86:1201-17. https://doi.org/10.3168/jds.S0022-0302(03) 73704-7

22. Martinez N, Risco CA, Lima FS, et al. Evaluation of peripartal calcium status, energetic profile, and neutrophil function in dairy cows at low or high risk of developing uterine disease. J Dairy Sci 2012;95:7158-72. https://doi.org/10.3168/jds.20125812

23.Zerbe H, Schneider N, Leibold W, Wensing T, Kruip TAM, Schuberth HJ. Altered functional and immunophenotypical properties of neutrophilic granulocytes in postpartum cows associated with fatty liver. Theriogenology 2000;54:771-86. https://doi.org/10.1016/S0093-691X(00)00389-7

24. Herdt TH. Ruminant adaptation to negative energy balance: influences on the etiology of ketosis and fatty liver. Vet Clin North Am Food Anim Pract 2000;16:215-30. https://doi.org/ 10.1016/S0749-0720(15)30102-X

25.Scalia D, Lacetera N, Bernabucci U, Demeyere K, Duchateau L, Burvenich C. In vitro effects of nonesterified fatty acids on bovine neutrophils oxidative burst and viability. J Dairy Sci 2006;89:147-54. https://doi.org/10.3168/jds.S0022-0302 (06)72078-1

26.LeBlanc S. Monitoring metabolic health of dairy cattle in the transition period. J Reprod Dev 2010;56(Suppl):S29-35. https:// doi.org/10.1262/jrd.1056S29

27. Sattler T, Fürll M. Creatine kinase and aspartate aminotransferase in cows as indicators for endometritis. J Vet Med A 2004;51:132-7. https://doi.org/10.1111/j.1439-0442.2004. 00612.x

28. House WA, Bell AW. Mineral accretion in the fetus and adnexa during late gestation in Holstein cows. J Dairy Sci 1993;76: 2999-3010. https://doi.org/10.3168/jds.S0022-0302(93)77639-0

29.van de Braak AE, van't Klooster AT, Malestein A. Influence of a deficient supply of magnesium during the dry period on the rate of calcium mobilisation by dairy cows at parturition. Res Vet Sci 1987;42:101-8. 